\title{
Core Flow-Through Appatatus: Letter Report Documenting Testing Phase
}

\author{
Brian Viani \\ Sue Martin
}

December 1, 1993

This is an informal report intended primarily for internal or limited external distribution. The opinions and conclusions stated are those of the author and may or may not be those of the Laboratory.

Work performed under the auspices of the U.S. Department of Energy by the Lawrence Livermore National Laboratory under Contract W-7405-ENG-48. 


\section{DISCLAIMER}

This document was prepared as an account of work sponsored by an agency of the United States Government. Neither the United States Government nor the University of California nor any of their employees, makes any warranty, express or implied, or assumes any legal liability or responsibility for the accuracy, completeness, or usefulness of any information, apparatus, product, or process disclosed, or represents that its use would not infringe privately owned rights. Reference herein to any specific commercial product, process, or service by trade name, trademark, manufacturer, or otherwise, does not necessarily constitute or imply its endorsement, recommendation, or favoring by the United States Government or the University of California. The views and opinions of authors expressed herein do not necessarily state or reflect those of the United States Government or the University of California, and shall not be used for advertising or product endorsement purposes.

This report has been reproduced directly from the best available copy.

Available to DOE and DOE contractors from the

Office of Scientific and Technical Information

P.O. Box 62, Oak Ridge, TN 37831

Prices available from (423) 576-8401

Available to the public from the

National Technical Information Service

U.S. Department of Commerce

5285 Port Royal Rd.,

Springfield, VA 22161 


\title{
Core Flow-Through Apparatus: \\ Letter Report Documenting Testing Phase
}

\author{
Brian Viani \\ Sue Martin \\ LLNL
}

\section{Introduction}

As part of the task of developing conceptual, physical and chemical, and performance models of the dynamics of water and dissolved and colloidal radionuclide constituents in the near-field, measurements of flow and transport properties of repository rocks and other near-field components are required. An apparatus has been fabricated that will be used to collect pertinent flow and transport data at temperatures expected in the near-field. Description of the core-flow apparatus (CFA) and preliminary testing results are included in this letter report.

The apparatus was designed to study the flow of radionuclide-bearing solutions through fractured or unfractured cylindrical samples of rock and other competent materials (e.g. concrete). Because near-field transport was the goal, the CFA was designed to be operated at elevated temperatures.

\section{Core-Flow Apparatus}

The CFA (Figure 1) allows a rock core-sample to be placed under confining pressure at temperatures to $200^{\circ} \mathrm{C}$ while an aqueous fluid containing tracers is pumped through. Flow, pressure, and temperature parameters are continuously monitored.

\section{Aqueous Fluid Flow System}

An aqueous solution is introduced to the system from a reservoir and pumped through the sample at a pore pressure $\left(\mathrm{P}_{\mathrm{P}}\right)$. Differential pressure $\left(\mathrm{P}_{\mathrm{D}}\right)$ across the core sample is set by adjusting upstream and downstream metering valves. Solutions containing tracers can be introduced to the system either in the reservoir or via a sample injection loop just prior to the sample vessel. A distribution plate spreads fluid across the end face of the core sample which is wrapped in Viton and confined between two Teflon end-plates in a pressure vessel (Figure 2). For elevated temperature tests, electrical resistance heating is used to maintain the sample at temperatures above ambient. Fluid exiting the rock sample can be sampled for chemical analysis or can be collected for measuring flow rate.

Setting pore and differential pressure - The aqueous fluid in the reservoir is pressurized using an electronically pulsed diaphragm type metering pump (Liquid Metronics Incorporated (Milton Roy Model A141-152S) which can pump at up to 17.3 bar with flow rates varying from 0.38 to $41.6 \mathrm{~mL} / \mathrm{min}$. The upstream pore pressure is controlled by a pressure release/pressure regulator ( $P_{\mathrm{P}}$ REG) that returns excess flow to the reservoir. The regulator release pressure is set by varying the tension on the release valve and is set to a maximum of $\sim 8 \mathrm{bar}$. The maximum operating pore 


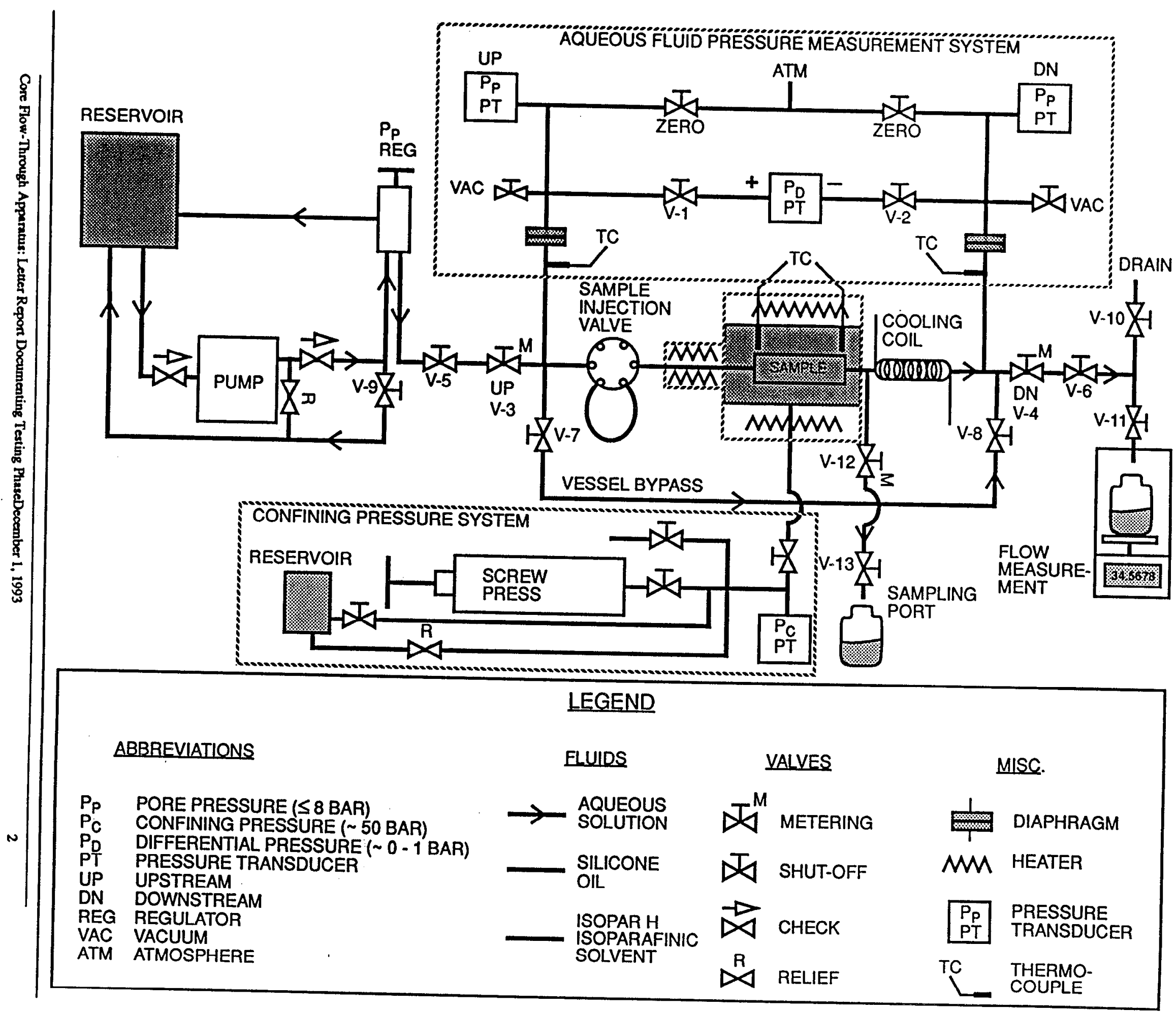




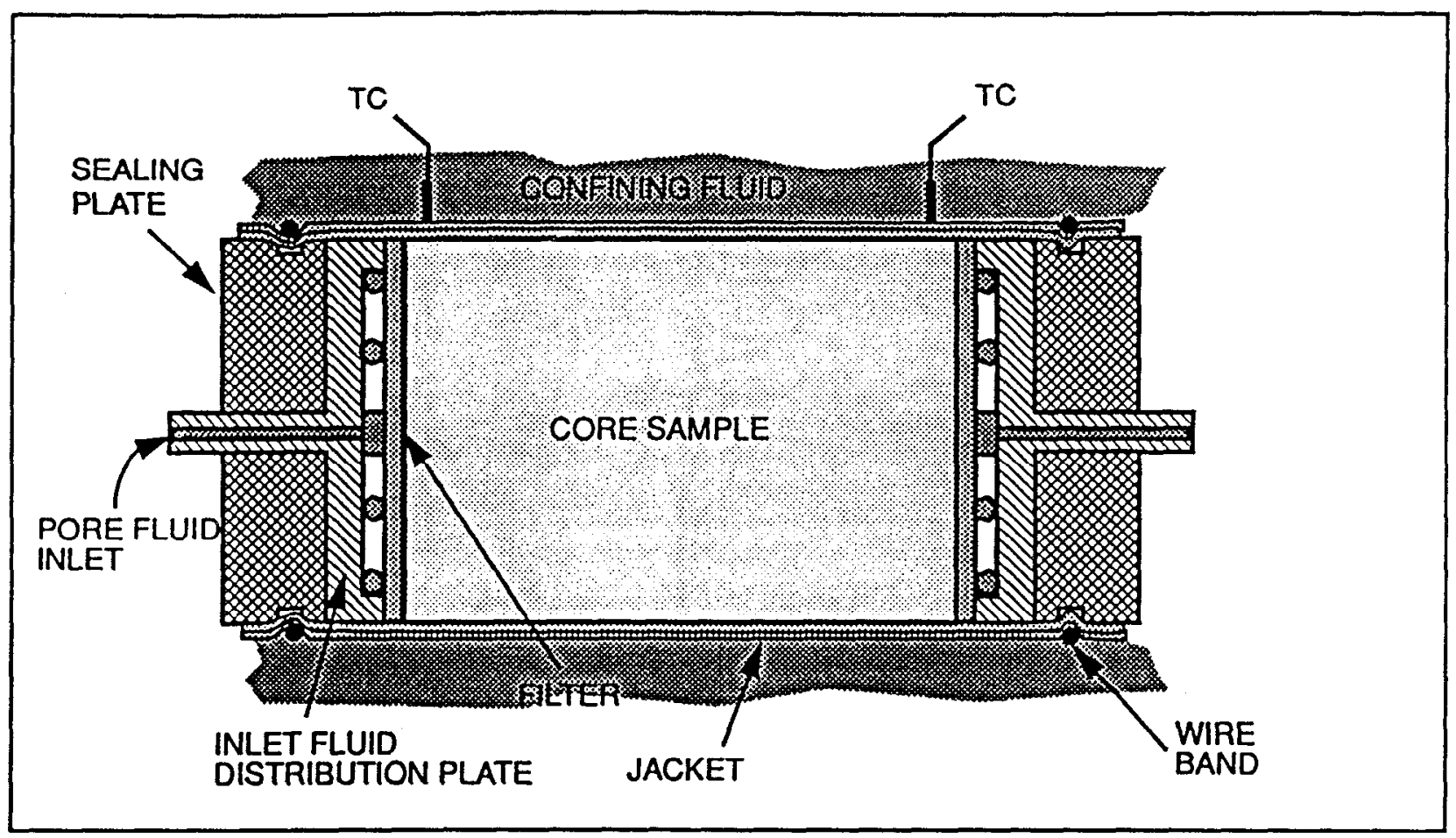

Figure 2. Schematic of core holder assembly.

pressure is limited by the strength of the Teflon flow lines and fittings to 13.1, 9.7,7.8,6.9, and 3.5 bar for ambient, $100,135,150$, and $200^{\circ} \mathrm{C}$ temperatures, respectively. The flow rate and differential pressure are controlled by adjusting the upstream and downstream metering valves. Differential pressures are adjusted to yield flow rates between approximately 0.05 and several $\mathrm{mL} / \mathrm{hr}$. The system operates at approximately constant pore pressure $( \pm 15 \%)$; differential pressure is more variable (see below).

Fluid sample injection valve - A liquid chromatography sample injection valve (Rheodyne Inc. Type 50 Model 5020) provides a means for injecting a sample under pressure between the upstream metering valve and the core sample. Fluid volumes for injection can be varied from fractions of a milliliter to several milliliters by adjusting the length and diameter of the sample loop (Figure 3). This valve is especially useful for injecting a tracer pulse to the sample.

Fluid and core-sample heating system - Prior to contacting the sample, the aqueous fluid is heated by an electrical resistance pre-heater maintained at the same temperature as the core sample. A similar heater maintains the temperature in the pressure vessel. The maximum operating temperature is $200^{\circ} \mathrm{C}$. Thermocouples at the entrance and exit end of the core sample monitor temperature which is controlled by separate temperature controllers (Fenwall, Model 550). Fluid leaving the sample is cooled to ambient temperature using water from a controlled temperature (Neslab Instruments Model RTE210) refrigerated recirculating water bath.

Sampling port - Fluid samples for chemical analysis may be collected prior to cooling, by closing off the downstream shut-off valve and opening the metering and shut-off valve on a line connected to the outflow from the core-sample. 


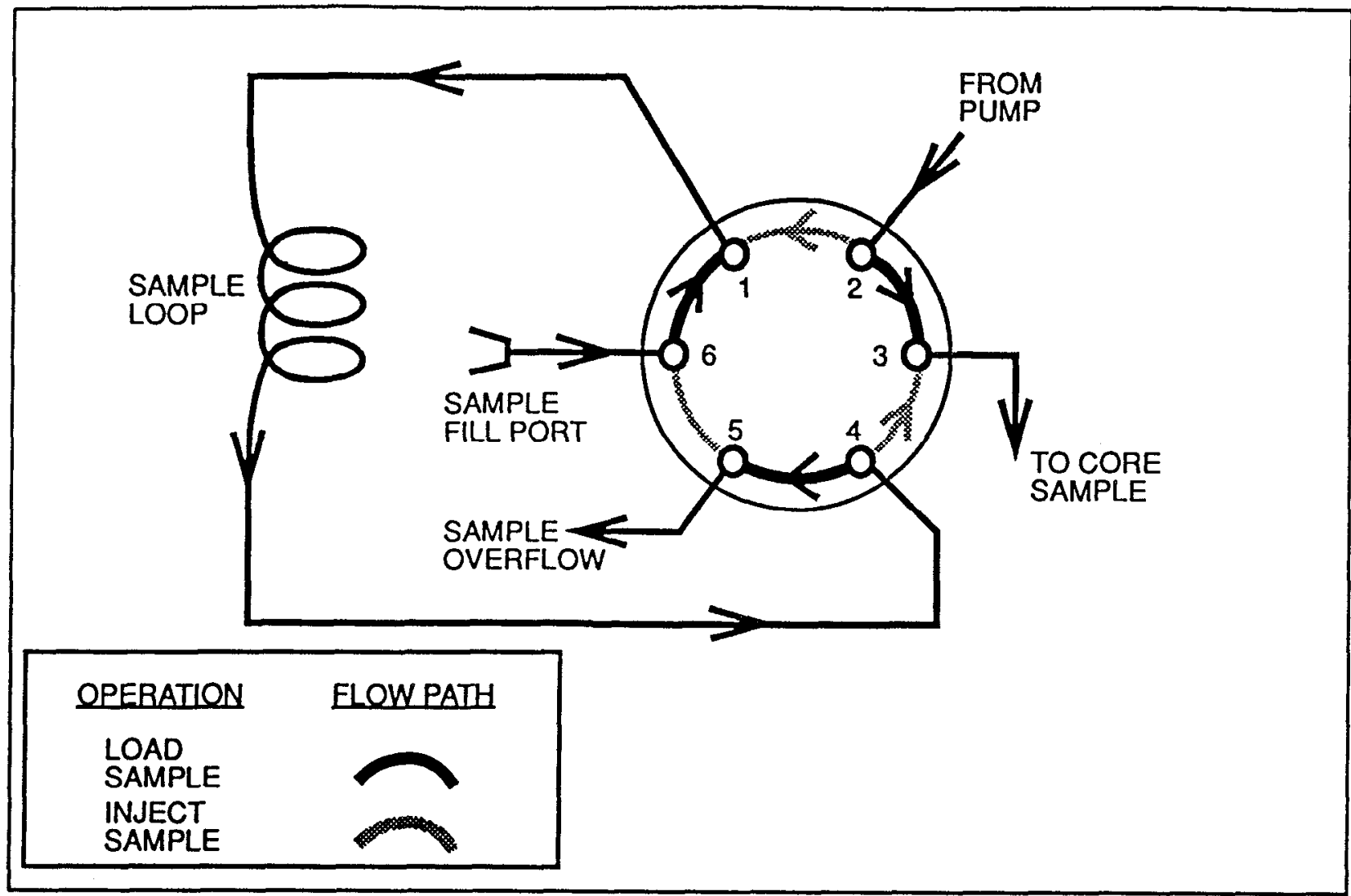

Figure 3. Sample injection valve.

Flow measurement - When flow measurements need to be taken, outflow fluid is collected in a bottle that is continuously weighed on a 5-place electronic balance (Mettler Instruments Model AE240). Fluid is directed into a collection bottle via a glass pipette that passes through ports in the balance chamber and the bottle cap. Evaporation from this system is very small; approximately $3.5 \mu \mathrm{L} / \mathrm{hr}$.

Materials contacting the aqueous fluid - With the exception of the fluid metering valves and the check balls used in the pump, the materials that contact the aqueous fluid are either Teflon or other polymeric materials (Table 1). When tracers are input to the system via the sample injection port, the materials contacted by the tracer before exiting at the sample collection port, besides the sample, are the Teflon flow lines, the Viton sample jacket, and the stainless steel metering valve at the collection port.

\section{Aqueous Fluid Pressure Measurement System}

Upstream and downstream pore pressure, and differential pressure transducers are isolated from the aqueous fluid system by Teflon diaphragms. The pressure measurement system is composed of stainless steel lines filled with silicone oil (Dow Corning 200 Silicone Fluid). The differential pressure transducer (Validyne Model P24D-44-1568, Range 0-25 psi) senses the difference in pressure between the upstream side of the sample injection valve and the downstream side of the cooling coil. Shut-off valves allow the differential pressure transducer to be isolated from the sys- 
Table 1: Component materials contacting aqueous fluid

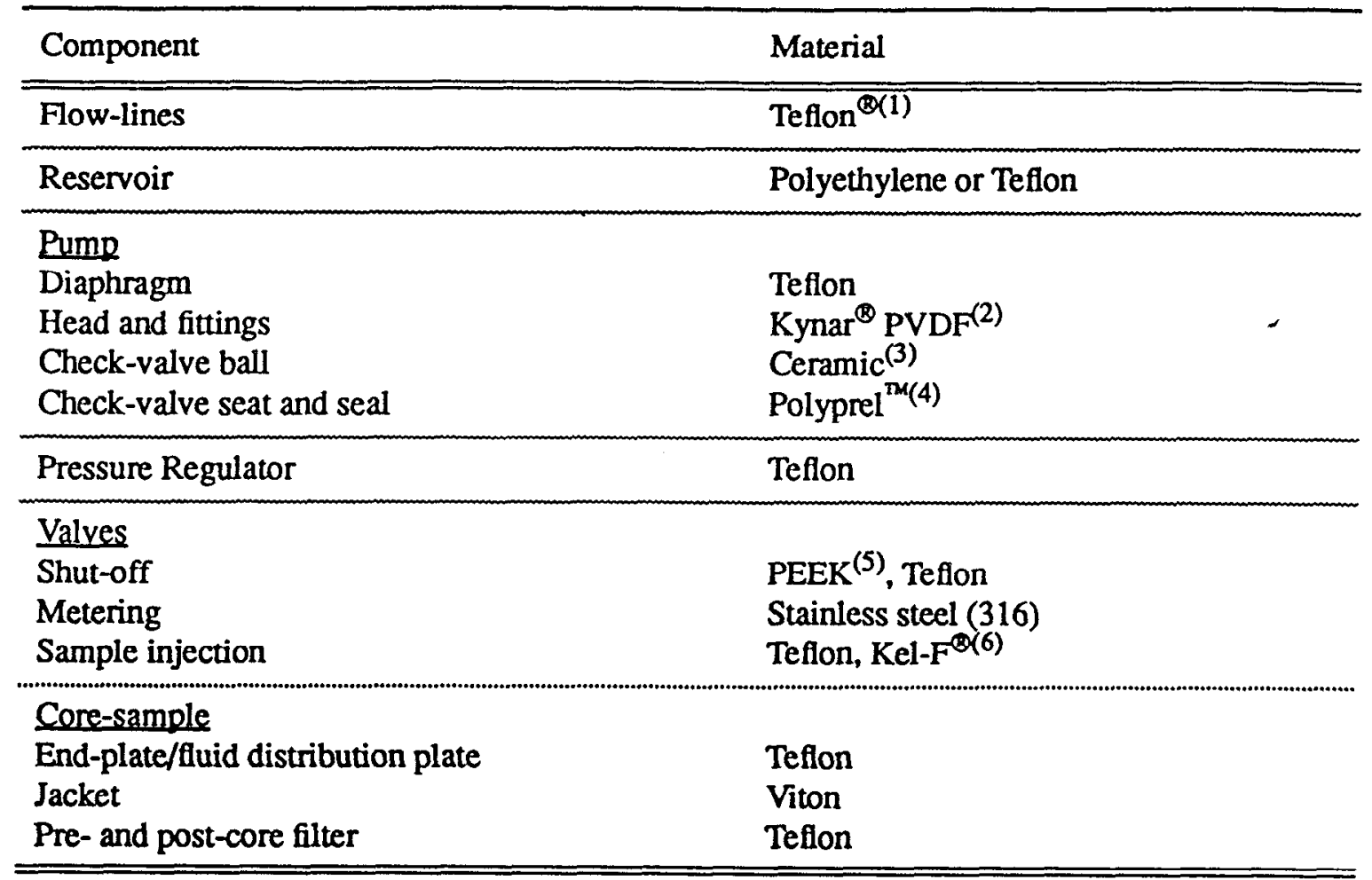

(1) Teflon ${ }^{8}$ is a trademark of E. I. du Pont de Nemours \& Co., Inc.

(2) $\mathrm{Kynar}^{\otimes}$ is a trademark of Pennwalt Corp. PVDF means polyvinylidenefluoride

(3) Alumina

(4) Polyprel is a trademark of LMI Corp.

(5) PEEK is polyetheretherketone.

(6) $\mathrm{Kel}-\mathrm{F}^{\otimes}$ is a trademark of $3 \mathrm{M} \mathrm{Co}$.

tem for experiments for which differential pressures in excess of 1 bar are necessary. Differential pressures are then calculated from the difference in readings between the upstream and downstream pore pressure transducers $\left(P_{P} P T\right)$ (Teledyne-Taber Model 2404, Range 0-150 psi). The two methods of measuring the differential pressure yield comparable results (Figure 4).

Temperature differences between the fluids on the aqueous fluid side of the diaphragms must be equal to insure that the measured pressures accurately reflect the pressure drop caused by the intervening core sample. The flow rate and/or temperature of the cooling water is adjusted to insure that upstream and downstream fluid temperatures (measured by thermocouples on the aqueous side of the pressure diaphragms) are equal.

\section{Confining Pressure System}

Confining pressures of approximately 50 bar (maximum operating pressure 62 bar) are maintained around the sample using an isoparafin type oil (ISOPAR $\mathrm{H}^{\mathrm{TM}}$; Exxon Co.) to prevent the aqueous fluid from flowing along the outside of the sample and to maintain fracture widths during heating. Confining pressures are developed using a screw press and pressure is monitored using a 


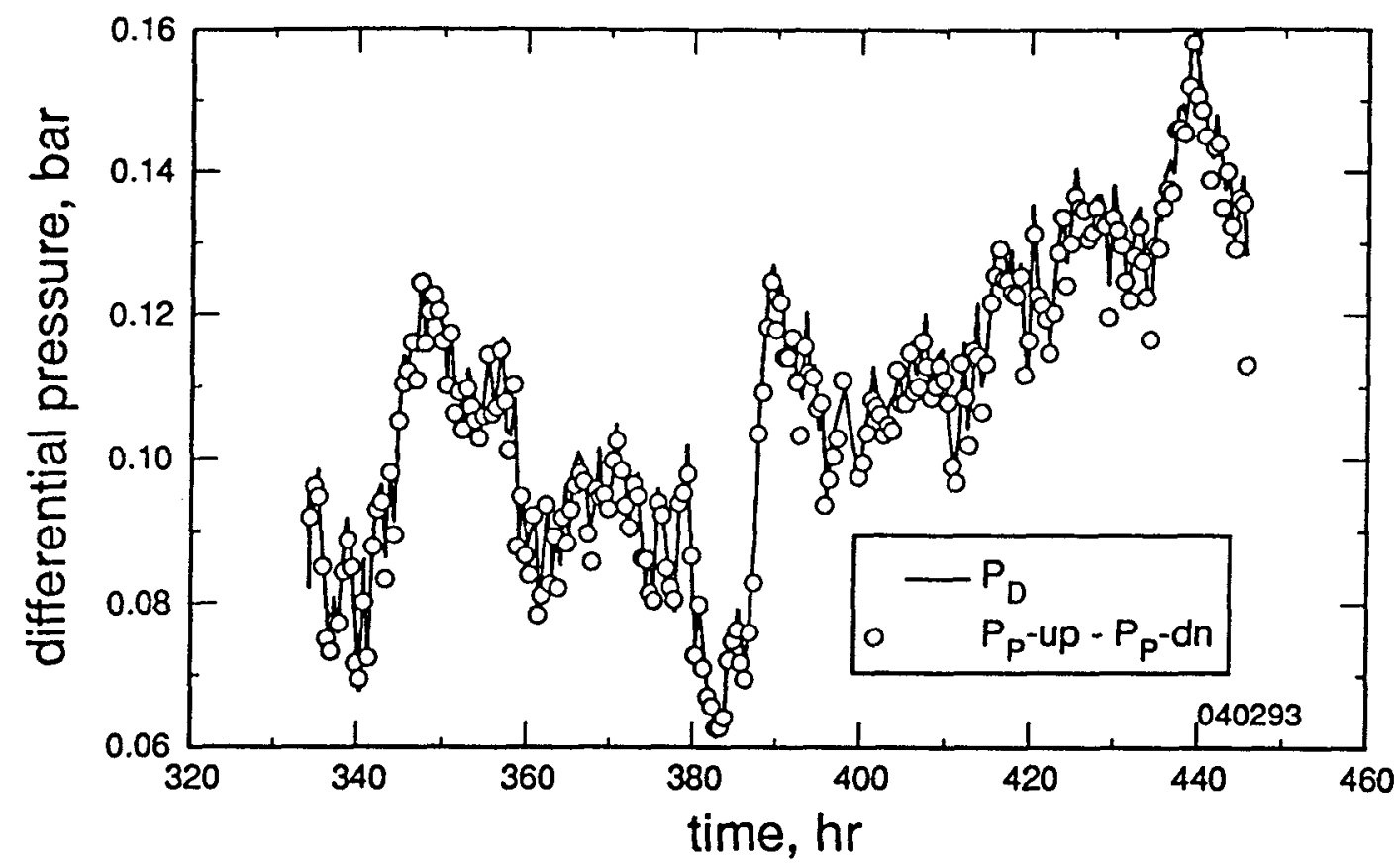

Figure 4. Comparison of differential pressure measured using the differential pressure transducer (solid line; $P_{D}$ ) vs. that determined from the difference in the upstream and downstream pressure transducers (open circles; $P_{\mathrm{P}}-\mathrm{up}-\mathrm{P}_{\mathrm{P}}-\mathrm{dn}$ ).

pressure transducer (Teledyne-Taber Model 2404, Range 0-1000 psi). The system is composed of stainless steel lines and valves.

\section{Data Collection, Storage, and Lab View system}

A variety of system variables are monitored and stored electronically using a Hewlett Packard data acquisition controller (Model HP3497A) in conjunction with LabVIEW data acquisition and instrument control software. Date, time, elapsed time, core-sample temperature, confining pressure, upstream and downstream pore pressure, differential pressure, and electronic balance reading are displayed on a monitor and stored in a computer file and/or printed to hardcopy. The frequency of sampling the system parameters and updating the monitor display (loop interval) is user controlled (generally 5 seconds or longer). Similarly, the frequency (storage interval) at which the sampled data is stored (appended) in a computer file or printed to hard copy is also user controlled (generally several minutes or longer).

\section{Core-Samples Used In Preliminary Testing}

Samples of Topopah Spring tuff used for the preliminary tests came from USW GU-3 (1153 foot depth; Id\# 00117348). Cylindrical samples were cored from larger pieces using deionized water as the cutting fluid. For the tests reported here, an artificial "fracture" was created by cutting the cylinder lengthwise using a diamond blade, lapping the cut surface on a 220 grit diamond resin board, and then manually finishing parallel to the core axis using $240 \mathrm{wet} / \mathrm{dry}$ abrasive. The sam- 
ple was then dried in a vacuum oven at $35^{\circ} \mathrm{C}$ until the core reached constant weight, and then rehydrated using filtered deionized water (milli-Q) until constant weight was obtained. The effective porosity, 8.64\%, was calculated from the bulk sample volume and the weight of imbibed water. Prior to assembling the sample in the CFA, the cut surfaces were cleaned by immersing in filtered deionized water and passing the tip of an ultrasonic probe over them to disperse the fine particles remaining from the cutting and lapping operations. Gold shims (0.001 x $0.125 \times 2.0$ in) were placed between the surfaces to maintain a known aperture.

\section{Preliminary Flow-Test Results}

A saw-cut sample with a fracture aperture of 0.001 in $(\sim 25 \mu \mathrm{m})$ was loaded into the CFA and sterilized by autoclaving the core in-situ by raising the temperature to $120^{\circ} \mathrm{C}$ for approximately 12 hours. After cooling to ambient temperature, the temperature was again raised to $120^{\circ} \mathrm{C}$ for 12 hours. The confining pressure was adjusted to approximately 50 bar. Pore pressure was maintained at approximately 5 bar. Filtered $(0.05 \mu \mathrm{m})$, deionized (milli-Q) water was pumped through the core during two flow tests lasting approximately 6 and 8 weeks (Figures 5 and 6 ).

At intervals, the collection bottle used to weigh the transmitted fluid was emptied and replaced on the balance. Cumulative data were obtained by splicing together the data sets for each collection interval. Despite sterilization of the core, both flow rate, differential pressure, and hydraulic conductivity varied, apparently as a result of bacterial fouling of the fracture aperture (see below). Diurnal variation of confining, pore, and differential pressure was also noted.

Hydraulic conductivity varied throughout both flow tests, but was especially evident for the first flow test (Figure 5) which also showed a relatively strong correlation between hydraulic conductivity and differential pressure not evident in the second test. The observed flow behavior suggested that the fracture gradually closed due to material filling the aperture, and that increasing the differential pressure resulted in this material being forced out. To test this, samples of the effluent fluid were taken at times when the flow rate and differential pressure were high (sample points indicated in Figure 5) and analyzed using transmission and scanning electron microscopy (TEM and SEM) to see if particles were present that could account for the decrease in hydraulic conductivity.

TEM and SEM analysis identified bacteria and inorganic particles in the effluent samples. The most abundant particles appeared to be rod shaped bacteria $(-1-1.5 \mu \mathrm{m}$ long) and were observed in all three samples (Figure 7). Although no obvious source of carbon was introduced into the system, and the core and input solutions were sterile, it is apparent that the growth of this bacterium was sufficient to essentially close the $25 \mu \mathrm{m}$ fracture aperture. Differential pressures on the order of 0.5 bar and flow rates on the order of $5 \mathrm{~mL} / \mathrm{hr}$ were necessary to "cleanse" the aperture. However, as shown in Figure 5, even after increasing the flow rate by increasing the differential pressure, closing of the aperture occurred subsequently. The current design of the CFA does not maintain constant flow or constant differential pressure and gradual closing of the aperture could occur because differential pressure and/or flow rate both decrease as the bacteria grow and attach on the walls of the fracture aperture. This phenomenon might not be observed using flow-through apparatuses for which constant flow is maintained (e.g., at a flow rate large enough to prevent bacterial attachment). 

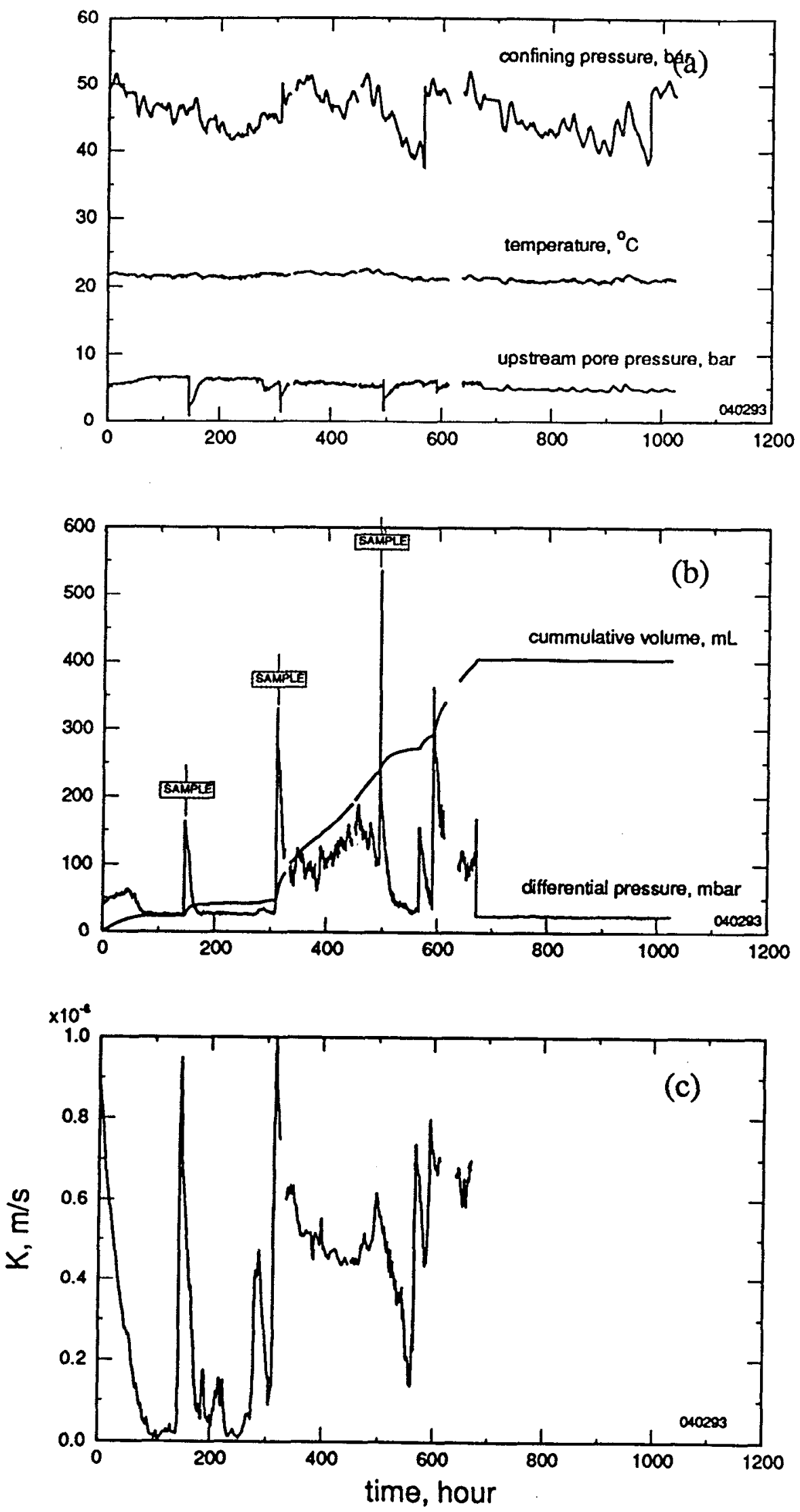

Figure 5. Summary of flow test 040293. (a) Confining and pore pressure, temperature; (b) Cumulative volume, differential pressure; (c) Hydraulic conductivity. 

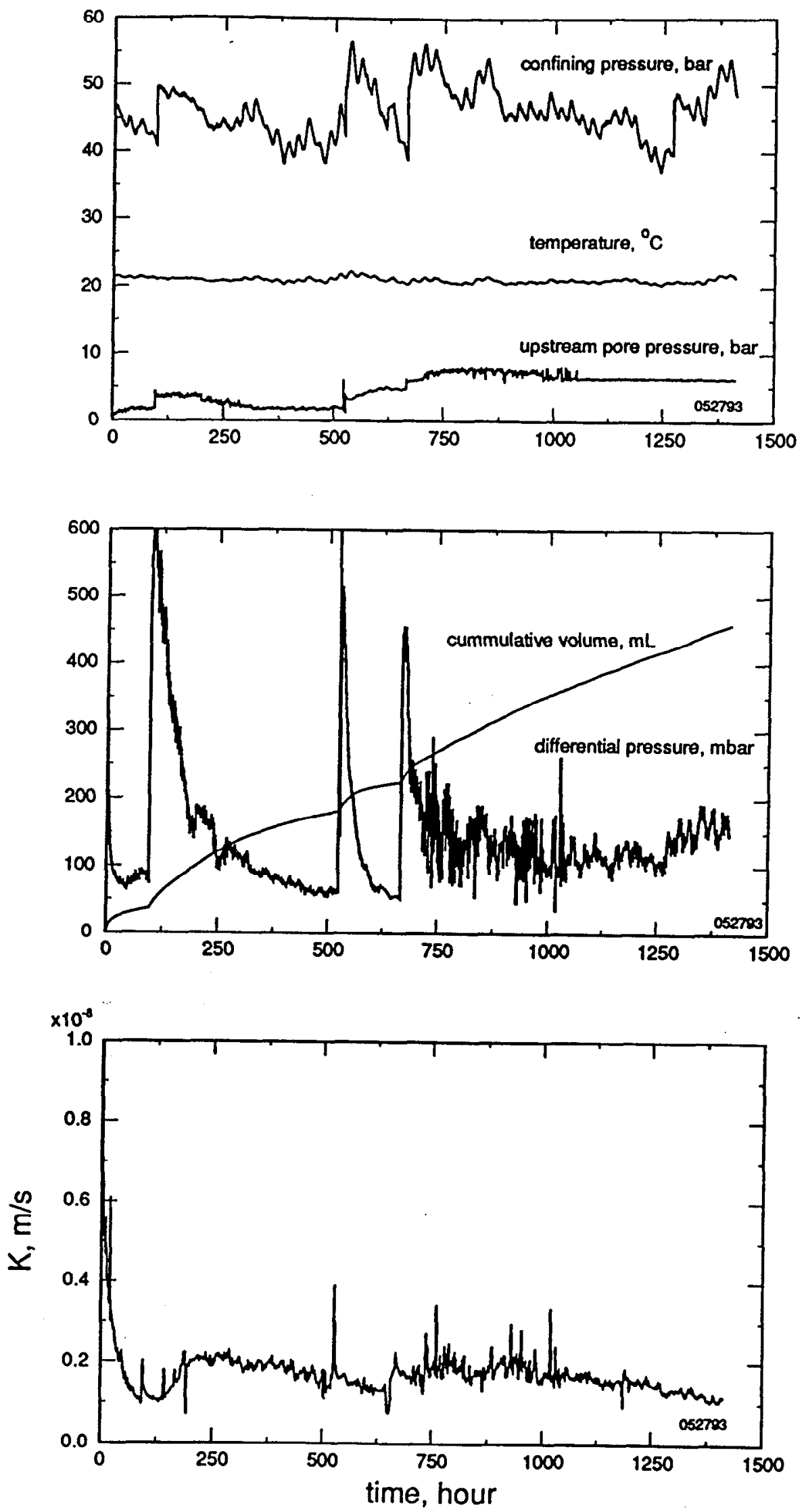

Figure 6. Summary of flow test 052793. (a) Confining and pore pressure, temperature; (b) Cumulative volume, differential pressure; (c) Hydraulic conductivity. 


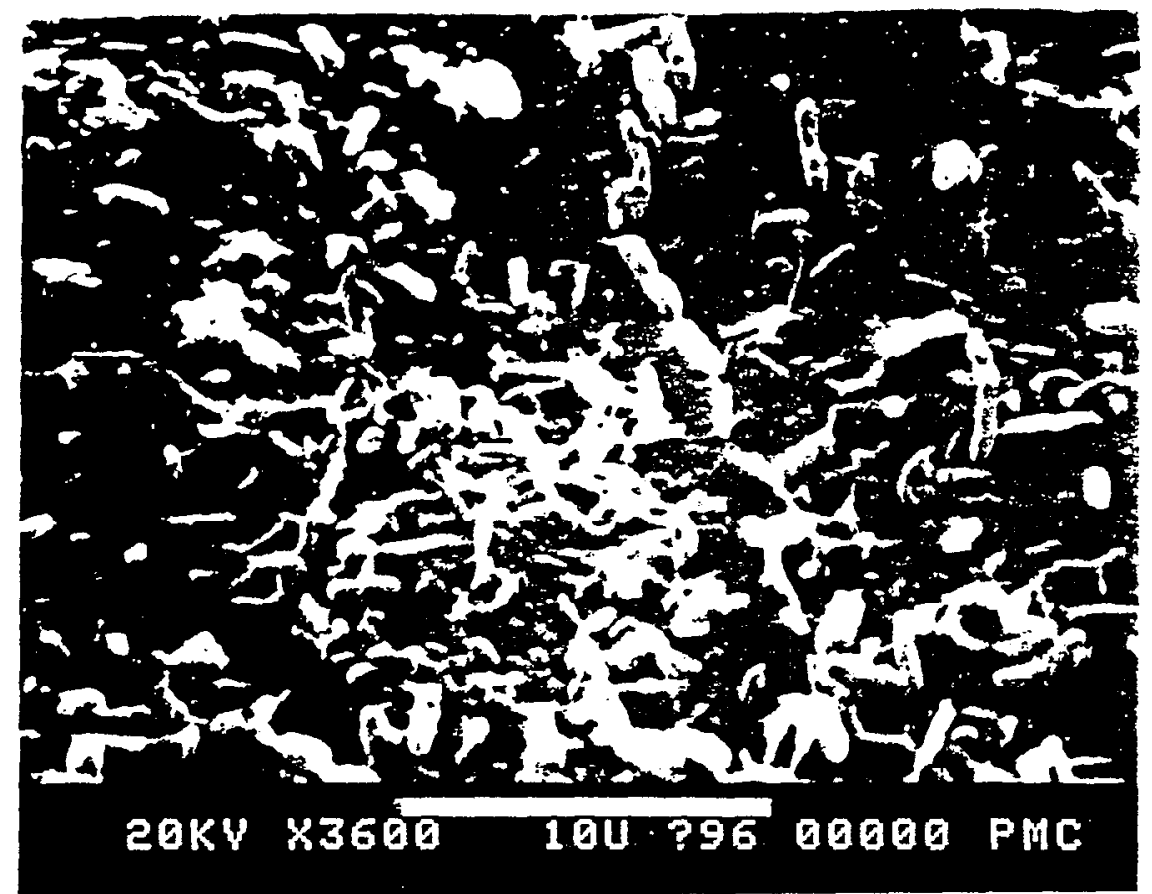

Figure 7. Micrograph of particles collected on polycarbonate filter from flow test (040293) showing abundance of rod-shaped bacteria.

The inorganic particles, which were much less abundant, were identified using TEM with energy dispersive $\mathrm{x}$-ray analysis and electron diffraction. These particles consisted of iron oxides (hematite) and layer silicates (mica, illite), and could be reasonably ascribed to the core sample or derived from the tools used to create the fracture.

The maximum flow rate observed was about 4-6 mL/hr. For the differential pressures applied, this value is much smaller than would be expected for a perfectly smooth fracture of the nominal aperture thickness defined by the shim material $(-25 \mu \mathrm{m})$ and corresponds to a fracture aperture of about 10-12 $\mu \mathrm{m}$. Possible explanations for this observation include: application of confining pressure may reduce the aperture width slightly; microbial growth results in a coating on the aperture that cannot be "cleansed" by high flow rates, and; at higher flow rates channels develop through the bacterial fracture "fill", hence, only part of fracture fill is removed and the effective lateral cross sectional area of the fracture is reduced. It was not possible to examine the fracture faces after the flow tests because of a temperature controller malfunction that resulted in confining fluid leaking into the core (see below).

\section{Future Modifications To Apparatus}

It is apparent from Figures 5 and 6 that variations in differential pressure and hydraulic conductivity are pronounced. These variations are due to changes in the core properties as a result of bacterial growth as well as to variations in confining pressure and pore pressure. Small diurnal temperature variations $\left( \pm 1^{\circ} \mathrm{C}\right.$ ) cause variations in confining pressure (Figure 8), and pore pressure. Variations in pore pressure are inversely related to variation in differential pressure (Figure 9). 


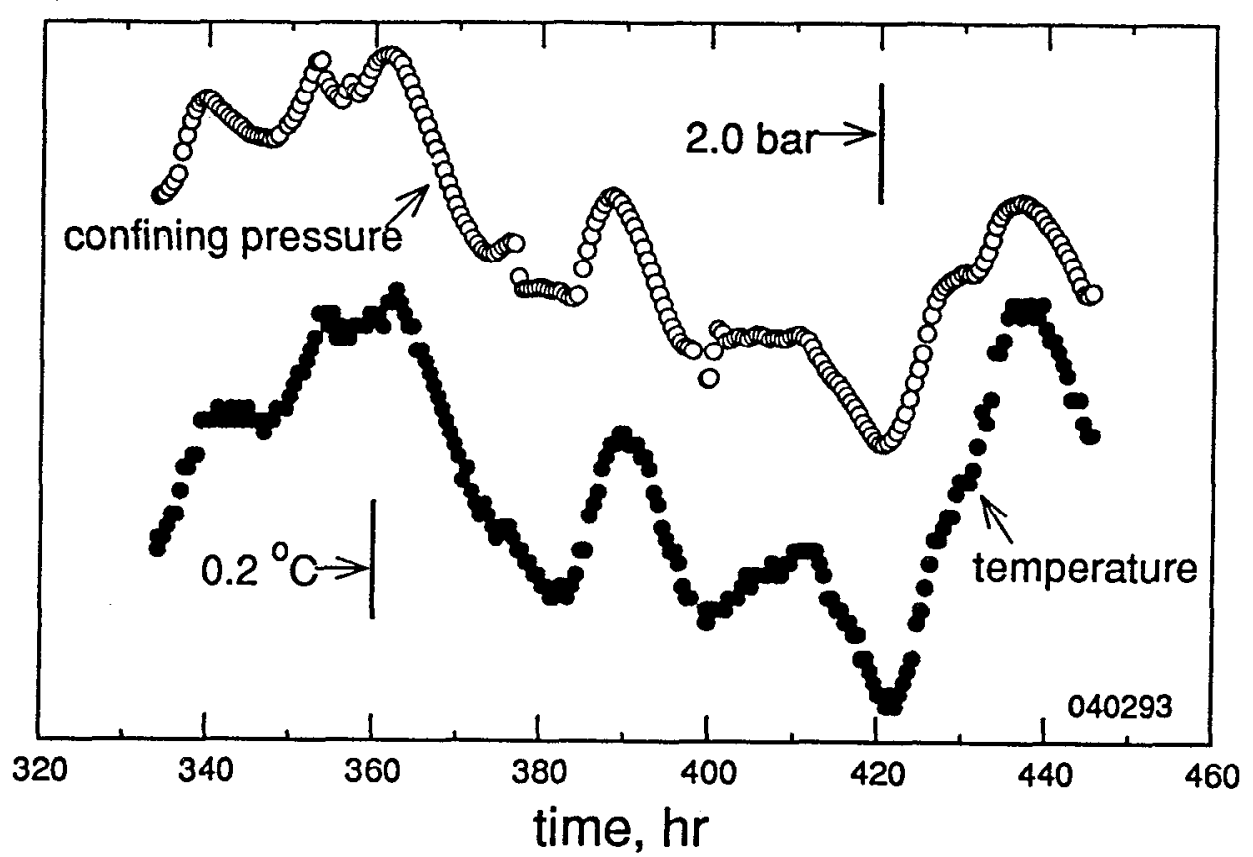

Figure 8. Comparison of variation of confining pressure (open circles) with variation in temperature (filled circles).

In order to maintain constant flow or constant differential pressure, the type of pump used will be changed from the diaphragm type to a piston type capable of maintaining very constant flow rates or upstream pore pressures (supplied by ISCO Inc.). Output from the pump will feed directly into the sample injection valve (Figure 1). The pump controller is capable of monitoring delivered volume as well as pressure and flow rate, hence, the balance used for measuring cumulative volume may be unnecessary. No changes will be made to the remainder of the system.

As a result of the temperature controller malfunction, the temperature at the core reached $300+$ ${ }^{\circ} \mathrm{C}$ and resulted in damage to the Tefion end plates and Viton gasket. The core sample was flooded with Isopar confining fluid as was much of the sample lines. Modifications to the temperature control system will be made to prevent this occurrence, and new Teflon lines will be installed.

\section{Future Experimental Plans}

Current plans call for reassembling the apparatus with the new pump and running room temperature and elevated temperature flow tests using an artificially fractured core. Following the flowtests, tracer tests at room temperature and elevated temperature will be made using $\mathrm{Br}^{-}$and possibly an organic dye as conservative tracers. These experiments will then be followed by tracer tests using $\mathrm{U}$ and $\mathrm{Np}$ bearing solutions. 


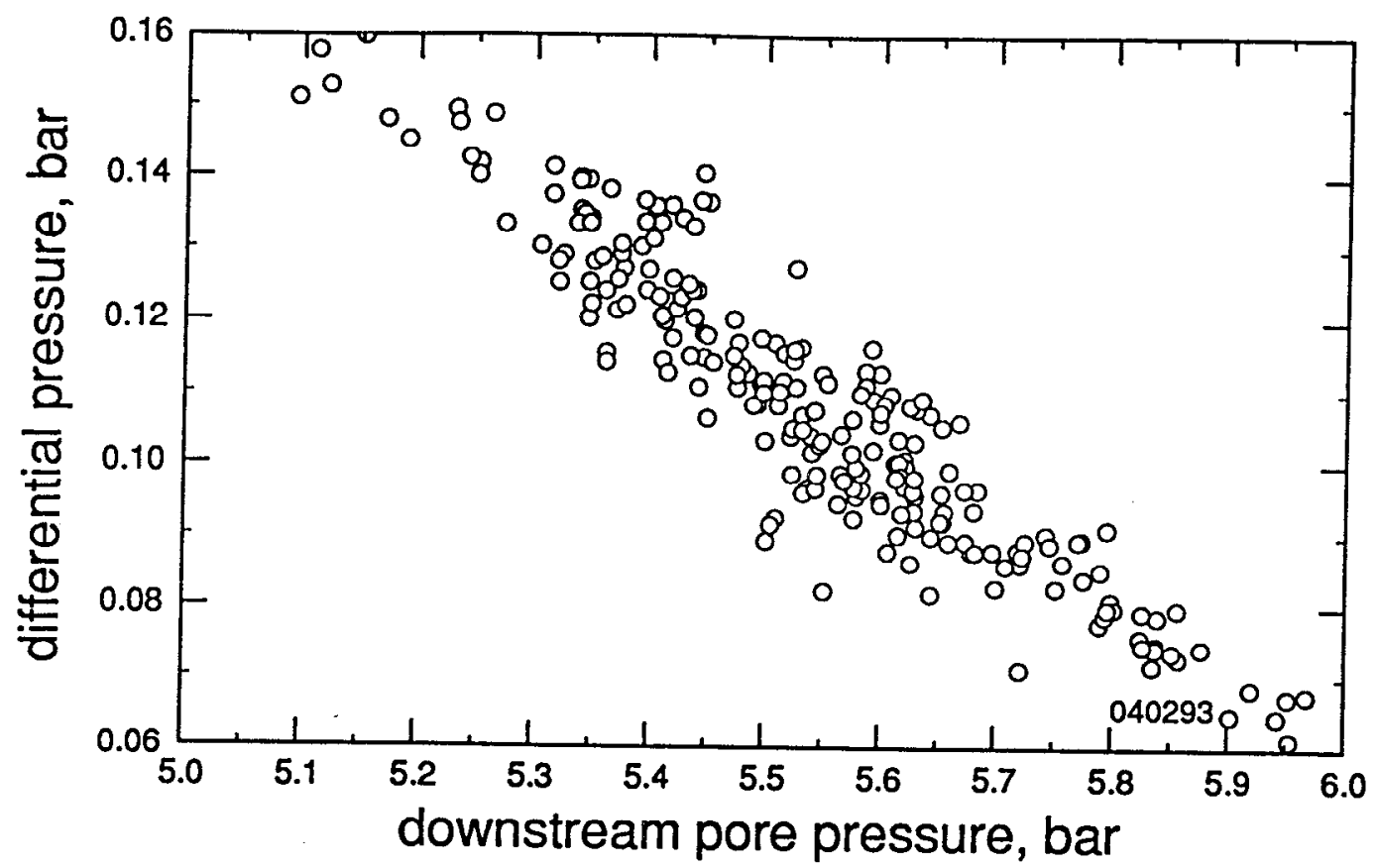

Figure 9. Relationship between differential pressure and pore pressure. 


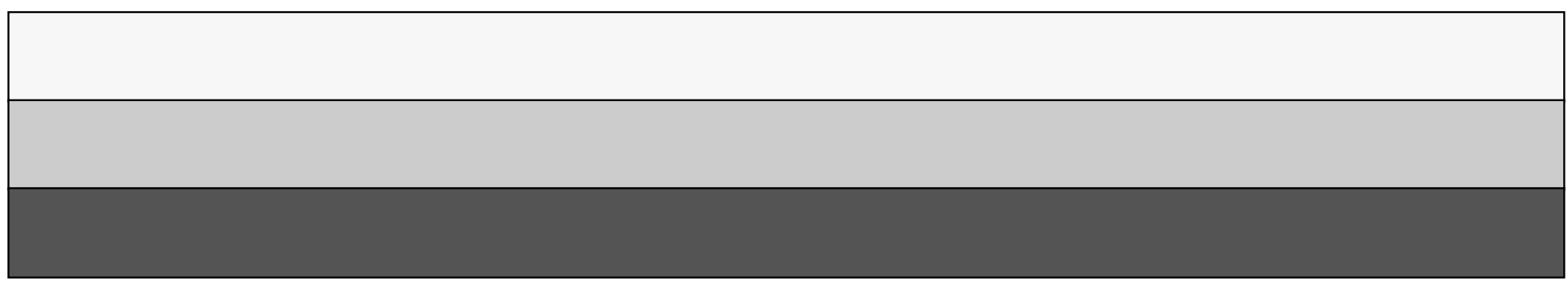

